\title{
Enhancing Grade 1 Thai Students' Learning about Mathematical Ideas on Addition Through Lesson Study and Open Approach
}

\author{
Naphaporn Woranetsudathip 1 \\ Chokchai Yuenyong ${ }^{*}$
}

\author{
${ }^{1}$ Khon Kaen University Demonstration Primary School, Khon Kaen, Thailand. \\ 2Faculty of Education, Khon Kaen Universtiy, Khon Kaen, Thailand. *Email: ychok@kku.ac.th
}

Doi:10.5901/mjss.2015.v6n2s1p28

\section{Abstract}

The paper aimed to enhancing Grade 1 Thai students' learning about mathematical ideas on addition through lesson study and open approach. The participants included 70 Grade 1 students in Khon Kaen University Demonstration School (Primary school level), Khon Kaen, Thailand. Methodology was qualitative research. Based on lesson study, teachers discussed how to enhance students' mathematical ideas on addition. And, they chose open approach to enhance students' mathematics learning. One of the teachers agreed to present the lesson based upon the lesson plan made cooperatively with his or her colleagues. Fellow teachers were active observers to notes on what happened in the classroom. All of the teachers then met again as a group for analysis, criticism and evaluation of the lesson plan in order to examine the appropriateness of teacher's performance, materials used and problems involved in enhancing students' learning about mathematical ideas on addition. Finally, teachers discussed necessary revisions to the lesson plan based on their observations and reflections. Data collected from observations of classroom teaching events, team reports, students' tasks, and individual reflections were analyzed qualitatively. The findings revealed that open approach for addition teaching enhanced 6 categories of mathematical ideas on addition including 1) whole counting, 2) counting on, 3) making ten, 4) factorization of the addends, 5) factorization of the augends, and 6) factorization of the addends and the factorization of the augends. It seemed that the majority of students' thinking processes were formed of making ten by using the blocks to explain their ideas. Teacher also needs to provide different ways of thinking and solving problem in order to help stimulate and encourage students to put their efforts in thinking for the solutions.

Keywords: mathematical ideas, addition, lesson study, open approach

\section{Introduction}

Thailand National Education Act (1999) was announced to begin educational reform in 1999. New curriculum construction was developed become more decentralized. The learning should be considered on learner-centred approach and lifelong learning (ONEC, 2000; Pitiyanuwat and Anantrasirichai, 2002). Learner-centred education evolved out of the constructivist paradigm of learning. Thai learning reform is based on the philosophy of constructivism. The ONEC (2000) gave the meaning of learner-centred approach as learning processes aimed at development of the person and the enrichment of their lives. Learners should be offered learning experiences to develop to their highest potential and in line with their aptitude, interests and needs. Learning activities should be organised with regard to individual differences. These activities should allow learners to interact to their whole environment and to apply learning methods to their daily life (ONEC, 2000: 26 - 27).

Mathematics learning also needs to be provided for construction of knowledge in the contexts. The mathematics problem would provide context for mathematics learning. Pehkonen (1995) suggested that supposed one solution of mathematics problem should not provide students learn mathematics related to the context. This type of problem was called a closed problem. He discussed that these problems could not enhance student divergent thinking. Therefore, the quality of education could not be shifted by the closed problem. In order to foster students to hold divergent thinking and reasoning, these closed problems should not be provided to the mathematics class. To go beyond a closed problem, the new contexts of mathematics problems should be introduced. These new contexts have to allow students to positively and actively learn. Gravemeijer and Doormann (1999) suggested that a constructive mathematics education should provide challenging tasks and an environment in order to allow students to construct their own concrete and informal problem solution strategies. In another word, the constructive mathematics tasks should allow students to explore 
experientially real and mathematically real context problems. The use of open-ended problems is another issue of provide learning environment for constructing mathematical knowledge. The use of open-ended problems in mathematics classrooms was initially discussed in the conference of PME-17, Tsukuba, Japan, in July 1993(Pehkonen, 1997).

\section{Literature Review}

\subsection{Open approach and mathematics learning}

Pehkonen (1997) explained growing up of the use of open-ended problems in mathematics classrooms which was considered in the PME-17. However, the history of open-ended problems tells us that it has been concerned by some groups of mathematics educators for long. The PME-17 discussion group on the open-ended problems in mathematics classrooms clarified existing ideas about this approach in many countries. It found that the method of using open-ended problems has been developed in Japan in the 1970's as "open-approach" method (Shimada 1977). In the same time, this type of problems was applied also in England as called "open-ended problems". The open-ended problems were used as mathematics investigations. It became popular in mathematics teaching (Wiliam, 1994), and the idea was spread more by Cockcroft-report (1982). Currently, some forms of open-ended problems in classroom were internationally applied. The research on this issues also was carried out in many countries (e.g. Nohda 1988, Pehkonen 1989, 1995, Silver \& Mamona 1989, Williams, 1989, Mason 1991, Nohda 1991, 1995, Stacey 1991, 1995, Zimmermann1991, Clarke \& Sullivan 1992, Silver 1993, 1995, Kadroon \& Inprasiha, 2011). However, they use a different name for open-ended problems in some countries. For example, in the Netherlands, they call their method "realistic mathematics" (Treffers1991).

The open approach is a pedagogical strategy that aims to enhance creative mathematics activities that encourage the students' curiosity and cooperation in the course of dealing with problems. Nohda (1995) proposed the view that open-ended problems are un-typified problems which should have two fundamentals. First, they should be provided as familiar and interesting subjects in order to fit to every student experiences. In another word, the problems should be flexible to handle by students who held different mathematical abilities. The problems should allow students to consider the need of solving problems, feel it possible to solve them with their own knowledge and have a sense of achievement after solving them. Second, open-ended problems should be not only appropriate for mathematical thinking but also could be generalized into new problems. They should also be provided in diverse levels where fit to many possible solutions. However, this approach can be fully realized whereby open-ended problems serve as a tool to bring out a fundamental change of class structure (Nohda, 2000).

The open approach was initially implemented in Thailand mathematics classroom in 2002 (Inprasitha, 2010). The open approach was provided in four phases. These included 1) Posing open- ended problem; 2) Students' self learning; 3) Whole class discussion and comparison; and 4) Summarization through connecting students' mathematical ideas emerged in the classroom (Kadroon \& Inprasiha, 2013). Currently, this framework of open approach was widely applied for Thailand mathematics classroom, particularly in Khon Kaen, Thailand.

It is quite new and challenge for us to enhance Grade 1 Thai students' learning about mathematical ideas on addition through open approach. Our teachers, who will implement open approach for mathematics teaching, need to find the appropriate ways of teaching mathematical ideas on addition through open approach in Thai contexts. To learn how to shift from traditional ways of mathematics teaching to open approach, it is essential for teacher to learn to teach mathematics through open approach within the context of real classrooms. Our teachers need also to improve mathematics teaching through open approach. As the premise behind lesson study, the most effective place to improve teaching is in the context of a classroom lesson (Stigler and Hiebert 1999). The lesson study may allow us to design and delivery of one mathematics lesson of mathematical ideas on addition through open approach.

\subsection{Lesson study}

Lesson study has been commonly used in Japan for curriculum development and the distribution of effective approaches to teaching (Lewis and Tsuchida 1998). This approach, developed in Japan, has a long history of engagement in most elementary and many middle schools since early 1990s. Currently, it is perceived as a professional development approach in many countries (Chokshi and Fernandez 2004). Thai Educators also learned to use Lesson study in many schools (Inprasitha, 2010).

Lesson study "offers a structure by which teachers transmit, reformulate, and share craft knowledge through practice and collaboration with peers" (Shimahara 2002, p. 113). Lewis (2000) proposed that the success lesson study 
should considered five characteristics. These included (1) lessons are planned collaboratively over a period of time; (2) the taught lessons are observed by other teachers; (3) the lessons should related to a particular goal or vision of learning; (4) the lessons are recorded; and (5) the lessons are discussed and shared with others.

A lesson study is collaborative planning of a research lesson. It should involves small groups around $4-6$ teachers who teach students in same level and/or content. When the planning begins they need to design the lesson by concerning on the goals of improving student learning outcomes. After the lesson is developed, a teacher from group will teach the lesson. And, the rest of group members will observe and collect data about the lesson process. The data collection may focus on students' learning for the specific topic taught, and the motivation, behaviours, attitudes and responses of the students towards learning. These varieties of sources and data were interpreted to reflect to the group as individual reflections. Regarding to these reflection, the team need to review and revise the lesson for the next teaching. Another team member then teaches the revised lesson to another class of pupils. Once again, observations are made and data gathered for further refinement. This lesson cycle could usually do in the Jugyou Kenkyu (Lesson Study) as a fundamental program in Japanese school-based in-service teacher training (Matoba, 2005). Matoba (2005) explained the lesson study as the cycle of plan, do, and see. "Plan", teachers discussed how to enhance students' mathematical ideas on addition. And, they chose open approach to enhance students' mathematics learning. "Do", one of the teachers agreed to present the lesson based upon the lesson plan made cooperatively with his or her colleagues. Fellow teachers were active observers during this class session and made ethnography notes on what happened in the classroom during the lesson. "Check", following the teaching of the lesson, all of the teachers then met again as a group for analysis, criticism and evaluation of the lesson plan. During this session they examined the appropriateness of teacher's performance, materials used and problems involved in enhancing students' learning about mathematical ideas on addition. "Action", teachers discussed necessary revisions to the lesson plan based on their observations and reflections, suggested improvement activities. However, the cycle of lesson study could be adapted for different contexts. Inprasitha (2010) suggested that lesson Study in Thai school could be implemented for three basic steps. These included collaboratively designing research lesson (Plan), collaboratively observing their friend teaching the research lesson (Do) and collaboratively doing post-discussion or reflection on teaching practice (See).

\section{Methodology}

Methodology was qualitative research. The study aimed to explain the phenomena of mathematics classroom how Grade 1 students were enhanced to learn about mathematical ideas on addition through open approach. And, we also examine how the cycle of lesson study support teachers to learn to improve the lesson plan of mathematical ideas on addition through open approach.

\subsection{Participants}

Participants included 147 Grade 1 students who were studying in KKU Demonstration School, Khon Kaen, Thailand.

\subsection{Open approach lesson plan of mathematical ideas on addition}

Open approach lesson plan of mathematical ideas on addition included 4 lesson plans including (1) how to, (2) 8+3, (3) $3+9$, and (4) 8+6. These Open approach lesson plans were provided regarded on four phases. These included 1) Posing open- ended problem; 2) Students' self learning; 3) Whole class discussion and comparison; and 4) Summarization through connecting students' mathematical ideas emerged in the classroom.

Based on lesson study, teachers discussed how to enhance students' mathematical ideas on addition. And, they chose open approach to enhance students' mathematics learning. One of the teachers agreed to present the lesson based upon the lesson plan made cooperatively with his or her colleagues. Fellow teachers were active observers to notes on what happened in the classroom. All of the teachers then met again as a group for analysis, criticism and evaluation of the lesson plan in order to examine the appropriateness of teacher's performance, materials used and problems involved in enhancing students' learning about mathematical ideas on addition. Finally, teachers discussed necessary revisions to the lesson plan based on their observations and reflections.

\subsection{Data collection and analysis}

Data were collected through direct observation of teaching episodes by researchers. The analysis of portfolios was 
carried out including reflective analyses of individual and team experiences and samples of planning and student-product artifacts. The direct observations were intended to (a) familiarize the researcher first hand with the classroom contexts, activities, and events of a number of the teaching episodes in order that (b) the researcher could verify the accuracy of the self-reported descriptions and reflections in the written documents. These could formulate what teachers learn to improve the open approach lesson plans. Students' mathematical ideas on the addition were categorized.

\section{Findings}

Two aspects of findings will be discussed including 1) students' learning about mathematical ideas on addition through open approach, and 2) teachers' learning about improving the lesson plan.

\subsection{Students' learning about mathematical ideas on addition through open approach}

Interestingly, Grade 1 students realize to solve the problems. The open-ended problems on addition allowed Grade 1 students to find various solutions at diverse levels. 1 . The students' mathematical ideas on the addition were categorized into 6 groups as follows:

1) In the whole counting, students counted each number in a set by counting numbers one by one in order to know all numbers in a set. The students were asked to place blocks over the objects they wanted to count. Thereafter, the students had the blocks to count one by one until they got them all and they put the blocks into its place so that they were able to understand the set of ten. It was called a base-ten system.

2) In the counting on, the students finished counting numbers in the first set. They started counting numbers in the second set by adding numbers one by one.

3) According to the base-ten system or making ten, the students added two numbers together in order to make ten or they brought the objects from the set to combine with the objects from another set for making ten.

4) The factorization of the addends, the students were required to consider which one was easy for them to separate between the number standing on top line or the addend. After the factorization of the students was observed, it showed that the students probably decided to separate the less ones. It was noticed that the students demonstrated the factorization of the addends by dividing the addends into two sets and they could plus the numbers with the augends in order to make ten.

5) In the factorization of the augends, the students followed the same way as they did in the factorization of the addends. When the students found that the factorization of the augends was easier, the students divided the numbers of the augends into two sets so that they could make ten by adding the numbers with the addends.

6) For the factorization of the addends and the factorization of the augends, if the numbers of the addends and the augends were closed and both of the two were too difficult for the students, the numbers should be separated into two sets so that the students could use them to make ten.

\subsection{Learning about improving the lesson plan}

It seemed that open-ended problems on addition could be sufficiently flexible to take into account the students' different mathematical abilities. The mathematical ideas of the students on the addition included the carry digits were involved with making ten. The students' process of thinking was formed of making ten by using the blocks to explain their ideas.

In the first activity, the students tried to use the blocks as a facilitator to help them find the whole numbers. The students understood how to make ten with the numbers included how to count the numbers which brought about the way to the use of symbols such as using the factorization of the addends and the factorization of the augends or using the factorization of the augends and the factorization of the addends. In the latest activity, the problem solving was begun at the beginning of the class. The students did not use the blocks and did not count for answering all the numbers. However, the students learned to apply the factorization of the addends and the factorization of the augends or the factorization of the augends and the factorization of the addends. Later on, they brought the blocks to apply in the explanation of making ten.

Teachers' questioning also could encourage developing students' process of thinking. The teacher asked the questions "try to think different ways" or "do you have any other ways for solving this problem?". These questions were to help stimulate and encourage students to put their efforts in thinking for the solutions. After the teacher implied these questions in the class frequently, the students tried to develop their thoughts from the concrete ideas such as placing the blocks over the objects and counting, counting the numbers one by one, or making ten. These ways brought to the 
abstract ideas such as using the factorization of the addends and the factorization of the augends or using the factorization of the augends and the factorization of the addends.

\section{Conclusion}

The developing open approach lesson plan about mathematics ideas on addition could give students a sense of achievement and fulfillment because it is possible even for students with less mathematical ability to set forth their own solutions within their own ability. The materials used in the open approach are very essential to the problem solving and the way the students explain or express their ideas. The students are able to understand the problems in the open situations by applying the solutions and explaining the ideas. The mathematical ideas of the students are occurred during the teacher uses the open approach. The main purpose is to study the thinking process on the addition and the explanation of the ideas with the various solutions. Therefore, the students are promoted to develop their thoughts and ideas.

\section{References}

Chokshi, S., \& Fernandez, C. (2004). Challenges to importing Japanese lesson study: Concerns, misconceptions, and nuances. Phi Delta Kappan, 85, 520-525.

Clarke, D.J. \& Sullivan, P.A. (1992). Responses to open-ended tasks in mathematics: characteristics and implications. In: Proceedings of the PME 16 (ed. W. Geeslin\& K. Graham). Volume I, 137-144.Durham (NH): University of NewHampshire.

Cockcroft Report (1982). Mathematics counts. Report of the Committee of Inquiry into the Teaching of Mathematics in Schools. London: H.M.S. .

Gravemeijer, K., \& Doorman, M. (1999). Context problem in realistic mathematics education: A calculus course as an example. Educational Studies in Mathematics, 39, 111-129.

Kadroon, T., \& Inprasiha, M. (2011). Teachers' values about teaching mathematics in classrooms; Implementing lesson study and open approach: A Thai experience. Journals of the Korean Society of Mathematics Education Series D, 15, pp. 115-126.

Kadroon, T., \& Inprasiha, M. (2013). Professional Development of Mathematics Teachers with Lesson Study and Open Approach: The Process for Changing Teachers Values about Teaching Mathematics. Psychology, 4(2): 101-105.

Lewis, C. (2000). Lesson study: The core of Japanese professional development. Invited address to the SIG on Research in Mathematics Education, AERA: New Orleans.

Lewis, C. C., \& Tsuchida, I. (1998, Winter). A lesson is like a swiftly flowing river. American Educator, 12-17, 50-52.

Mason, J. (1991). Mathematical problem solving: open, closed and exploratory in the UK. International Reviews on Mathematical Education (= ZDM) 23 (1), 14-19.

Matoba, M. (2005). Improving Teaching and Enhancing Learning: A Japanese Perspective. The First Annual Conference on Learning Study, The Hong KongInstitute of Education, 1-3 December 2005

Nohda, N. (1988). Problem solving using "open-ended problems" in mathematics teaching. In: Problem Solving - A World View (eds. $\mathrm{H}$. Burkhardt, S. Groves,A. Schoenfeld \& K. Stacey), 225-234. Nottingham: Shell Centre.

Nohda, N. (1991). Paradigm of the "Open-approach" method in mathematics teaching: Focus on mathematical problem solving. International Reviews on Mathematical Education (= ZDM) 23 (2), 32-37.

Nohda, N. (1995). Teaching and Evaluating Using "Open-Ended Problem" in Classroom. International Reviews on Mathematical Education (= ZDM) 27 (2), 57-62.

Nohda, N. (2000). Teaching by open-approach method in Japanese mathematics classroom. Proceeding of the 24th conference of the international Group for the Psychology of Mathematics Education, Hiroshima, Japan, July 23-27, volume 1-39-53.

Office of the National Education Commission (ONEC). (2000). Learning Reform: A Learner-Centred Approach. Bangkok, Thailand: Wattana Panit Printing \& Publishing Company Limited.

Pehkonen, E. (1989). Der Umgang mit Problem feldern im Mathematikunterricht der Sek. I.In: Beitrage zum Mathematikunterricht 1989, 290-293.Verlag Franzbecker, Bad Salzdetfurth.

Pehkonen, E. (ed.) 1995. Using Open-ended Problems in Mathematics Class. International Reviews on Mathematical Education (= ZDM) 27 (2), 55-72.

Pehkonen, E. (1995). Using open-ended problem in mathematics. Zentralblatt fur Didaktik der Mathematik, 27(2), 67-71.

Pehkonen, E. (1997). Use of Open-Ended Problems in Mathematics Classroom.Research Report. Helsinki, Finland.

Pitiyanuwat, S. and Anantrasirichai, A. (2002). Curriculum and learning reform in Thailand. Paper presented at Invitational Curriculum Policy Seminar: School Based Curriculum Renewal for the Knowledge Society Developing Capacity for New Times, Hong Kong, 14 - 16 November 2002. Available: http://ci-lab.ied.edu.hk

Shimada, S. (ed.) (1977). Open-end approach in arithmetic and mathematics - A new proposal toward teaching improvement. Tokyo: Mizuumishobo. [in Japanise] ${ }^{\star}$

Shimahara, N. K. (2002). Teacher professional development in Japan. In G. DeCoker (Ed.), National standards and school reform in Japan and the United States (pp. 107-120). New York: Teachers College Press. 
Silver, E.A. \& Mamona, J. (1989). Problem posing by middle school mathematics teachers. In: Proceedings of PMENA 11 (eds. C.A. Maher, G.A. Goldin \& R.B.Davis). Volume 1,263-269. New Brunswick (NJ): Rutgers University.

Stacey, K. (1991). Linking application and acquisition of mathematical ideas through problem solving. International Reviews on Mathematical Education (= ZDM) 23(1), 8-14.

Stacey, K. (1995). The Challenges of Keeping Open Problem-Solving Open in School Mathematics. International Reviews on Mathematical Education (= ZDM) 27(2), 67-72.

Treffers, A. (1991). Realistic mathematics education in The Netherlands 1980-1990. In: Realistic mathematics education in primary school (ed. L. Streefland), 11-20.Utrecht: Freudenthal Institute.

Wiliam, D. (1994). Assessing authentic tasks: alternatives to mark-schemes. Nordic Studies in Mathematics Education, 2 (1), 48-68.

Williams, D. (1989). Assessment of open-ended work in the secondary school. In: Evaluation and Assessment in Mathematics Education (ed. D. F. Robitaille),135-140.Science and Technology Education. Document Series 32.Paris:Unesco.

Zimmermann, B. (1991). Offene Probleme fur den Mathematikunterricht and ein Ausblick auf Forschungsfragen.In: International Reviews on Mathematical Education (= ZDM) 23 (2), 38-46. 